\title{
Stability of Si-O-F low-K dielectrics: Attack by water molecules as function of near-neighbor Si-F bonding arrangements
}

\author{
H. Yang a) \\ Department of Chemistry, North Carolina State University, Raleigh, North Carolina 27695-8204 \\ G. Lucovsky ${ }^{\text {b) }}$ \\ Department of Physics, Materials Science and Engineering and Electrical and Computer Engineering, \\ North Carolina State University, Raleigh, North Carolina 27695-8202
}

(Received 2 February 1998; accepted 9 March 1998)

\begin{abstract}
$A b$ initio configuration interaction calculations have been previously used to account for the relatively large decreases in the static dielectric constant of Si-O-F alloys with low alloy concentrations of $\mathrm{F}$ atoms, $\sim 22 \%$ for $\mathrm{F}$ concentrations of $\sim 10$ at. $\%$. The present study addresses the stability of these alloy films with respect to attack of Si-F bonds by water molecules. The present calculations show that the reaction: $\mathrm{H}_{2} \mathrm{O}+2 \mathrm{Si}-\mathrm{F} \rightarrow 2 \mathrm{HF}+\mathrm{Si}-\mathrm{O}-\mathrm{Si}$ is exothermic by about $0.7 \mathrm{eV}$. Our calculations focus on the reaction energetics and geometries as a function of the distance between the $\mathrm{F}$ atoms of the Si-F groups and water molecules. Combining these calculations for interactions with $\mathrm{H}_{2} \mathrm{O}$ with a statistical model of bonding in the alloy films as presented in our previous article, an upper limit for chemically stable F corporation has been determined to be $\sim 10-12$ at. \% F, which corresponds to static dielectric constant of 3.2-3.4. (C) 1998 American Institute of Physics. [S0734-2101(98)58303-0]
\end{abstract}

\section{INTRODUCTION}

There is considerable interest in insulating films with static dielectric constants, $\epsilon_{\mathrm{s}}$, lower than $\mathrm{SiO}_{2}$. One alloy system that has attracted considerable attention is $\mathrm{Si}-\mathrm{O}-\mathrm{F}$ or fluorinated silicon oxide, $\mathrm{SiO}_{2}: \mathrm{F}$. Previously we have studied and discussed the reduction of the static dielectric constants of Si-O-F alloy films deposited by chemical vapor deposition with respect to those of similarly prepared $\mathrm{SiO}_{2}$ films in terms of infrared (IR) absorption spectra and contributions of electronic and vibrational transitions to $\epsilon_{s}{ }^{1} A b$ initio configuration interaction calculations were then used to identify inductive effects of $\mathrm{Si}-\mathrm{F}$ bonds on the properties of $\mathrm{Si}-\mathrm{O}-\mathrm{Si}$ groups that are back bonded to the $\mathrm{Si}$ atom of that $\mathrm{Si}-\mathrm{F}$ group. ${ }^{1}$ Our ab initio calculations provide a theoretical framework for understanding why relatively small additions of $\mathrm{F}$ atoms to $\mathrm{SiO}_{2}, \sim 10-12$ at. \%, produce significant decreases in $\epsilon_{s}, \sim 22 \%$, from approximately $4.1 \pm 0.1$ in $\mathrm{SiO}_{2}$ deposited by low pressure chemical vapor deposition (LPCVD) to $\sim 3.2-3.4$.

The present study addresses the stability of the Si-O-F alloy films with respect to attack of Si-F bonds by water molecules. IR data have shown that the Si-O-F films are hydroscopic. ${ }^{2,3}$ Spectra presented in Ref. 3 indicate two features in the $\mathrm{OH}$ absorption regime: (i) one with a spectral peak at $\sim 3650 \mathrm{~cm}^{-1}$ and an asymmetric line shape that has been assigned to $\mathrm{Si}-\mathrm{OH}$ groups with $\mathrm{H}$-bonding interactions with a random distribution of $\mathrm{O}$ neighbors, and (ii) a second with a spectral peak at $\sim 3300 \mathrm{~cm}^{-1}$ and a symmetric line shape that is due to near-neighbor pairs of $\mathrm{Si}-\mathrm{OH}$ groups. ${ }^{4}$ The $3300 \mathrm{~cm}^{-1}$ band is assigned to postfilm formation water absorption via the reaction pathway given as:

\footnotetext{
${ }^{a)}$ Electronic mail: hong_yang@ncsu.edu

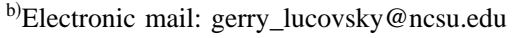

$$
2 \mathrm{H}_{2} \mathrm{O}+\{\mathrm{Si}-\mathrm{F}+\mathrm{Si}-\mathrm{F}\} \rightarrow\{\mathrm{Si}-\mathrm{OH} \cdots \mathrm{Si}-\mathrm{OH}\}+2 \mathrm{HF},
$$

where the " \{\} " notation indicates nearest neighbors and the " "..." notation indicates a paired $\mathrm{H}$-bonding interaction, i.e., the $\mathrm{H}$ atom of each $\mathrm{OH}$ group interacts via a $\mathrm{H}$ bond with the $\mathrm{O}$ atom of the neighboring $\mathrm{OH}$ group. This pairing of $\mathrm{OH}$ bonds has also been attributed as H-OH bonding in Ref. 3 .

The near-neighbor $\{\mathrm{Si}-\mathrm{OH} \cdots \mathrm{Si}-\mathrm{OH}\}$ configurations can be removed by relatively low temperature thermal annealing as in Ref. 4 via the following reaction:

$$
\{\mathrm{Si}-\mathrm{OH} \cdots \cdot \mathrm{Si}-\mathrm{OH}\} \rightarrow \mathrm{Si}-\mathrm{O}-\mathrm{Si}+\mathrm{H}_{2} \mathrm{O}
$$

so that combined effect of atmospheric exposure and annealing is to reduce the bonded $\mathrm{F}$ content. The reaction pathway attack of the Si-O-F film by water was through near-neighbor $\mathrm{F}$ atom bonding sites, e.g., those with paired $\mathrm{Si}-\mathrm{F}$ atom bonding arrangements. Since these dominate when the fraction of $\mathrm{Si}-\mathrm{F}$ bonding sites occupied exceeds 0.2 of those available, we can expect hydroscopic behavior to become increasingly important when the $\mathrm{F}$ atom concentration begins to exceed $\sim 7$ at. \% (note that for a structural model that assumes only Si-F bonding arrangement complete occupancy of available $\mathrm{F}$ atom bonding sites corresponds to $\sim 28.6$ at. \% F). This restricted bonding model has been assumed for the low Fcontent alloys of this study.

The present article studies the stability of the Si-O-F alloy films with respect to attack of Si-F bonds by water molecules. Our calculations focus on the reaction energetics and geometries as a function of the distance between the $\mathrm{F}$ atoms of the Si-F groups.

\section{THEORY AND CALCULATIONS}

Total energy calculations are performed using a manyelectron embedding theory that permits the accurate compu- 


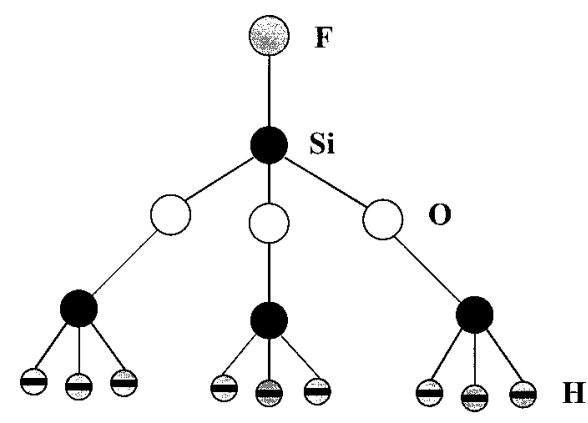

FIG. 1. Cluster geometry used to model the Si-O-F alloy film.

tation of molecule-solid surface interactions. Calculations are carried out at an $a b$ initio configuration interaction (CI) level, i.e., all electron-electron interactions are explicitly calculated and there are no exchange approximations or empirical parameters. The details of the method are extensively discussed in Refs. 5-7.

Calculations are performed by first obtaining selfconsistent-field (SCF) solutions for the $\mathrm{Si}-\mathrm{O}-\mathrm{F}$ cluster plus water molecule. The occupied and virtual orbitals of the SCF solution are then transformed separately to obtain orbitals spatially localized within the $\mathrm{Si}-\mathrm{F}$ bonds and $\mathrm{H}_{2} \mathrm{O}$ molecule. This unitary transformation of orbitals which is based upon exchange maximization with atomic valence orbitals enhances convergence of the configuration interaction expansion. $^{5-7}$

The dominant SCF configuration with several other configurations, selected with a coefficient $>0.05$ in the initial expansion, defines the multiconfiguration expansion of $\psi_{0}$. Configuration interaction expansions, $\psi$, are generated from $\psi_{0}$, by single and double excitations, to give excited configurations, $\psi_{k}, \psi=\psi_{0}+\Sigma_{k} c_{k} \psi_{k}$.

Configurations are retained if an interaction threshold

$$
\left.\left\langle\psi_{k}|H| \psi_{0}\right\rangle\right|^{2} /\left(E_{k}-E_{0}\right)>1.0 \times 10^{-5} \text { hartree }
$$

is satisfied. In the present work CI expansions contain approximately 5000-7000 configurations. Contributions of excluded configurations are estimated using second-order perturbation theory. The inclusion of several other configurations as reference states besides the SCF dominant configuration increases the correlation energy by increasing variational degrees of freedom.

The Si-O-F cluster used in the present study is shown in Fig. 1. The silicon atom bonded to the F atom is described at an all electron level by Dunning's [6s4p] basis sets contracted from $[11 \mathrm{~s} 7 \mathrm{p}]$ primitive sets of Huzinaga, ${ }^{8}$ augmented by a set of $\mathrm{d}$ polarization functions with an exponent of 0.4 . Other silicon atoms are described at the $3 \mathrm{~s}$, 3p valence electron level by a set of double-zeta five term $3 \mathrm{~s}$ and four term $3 \mathrm{p}$ basis functions used by Chattopadhyay et al. ${ }^{9}$ and a [1s$2 \mathrm{p}$ ] effective core potential. The double-zeta $\mathrm{s}$ and $\mathrm{p}$ basis for oxygen and fluorine are taken from Whitten ${ }^{10}$ and augmented with a set of $d$ functions with the same exponent of 0.8 . For the hydrogen atoms saturating the secondary silicon atoms, a double-zeta s basis is used. The hydrogen atoms of the water

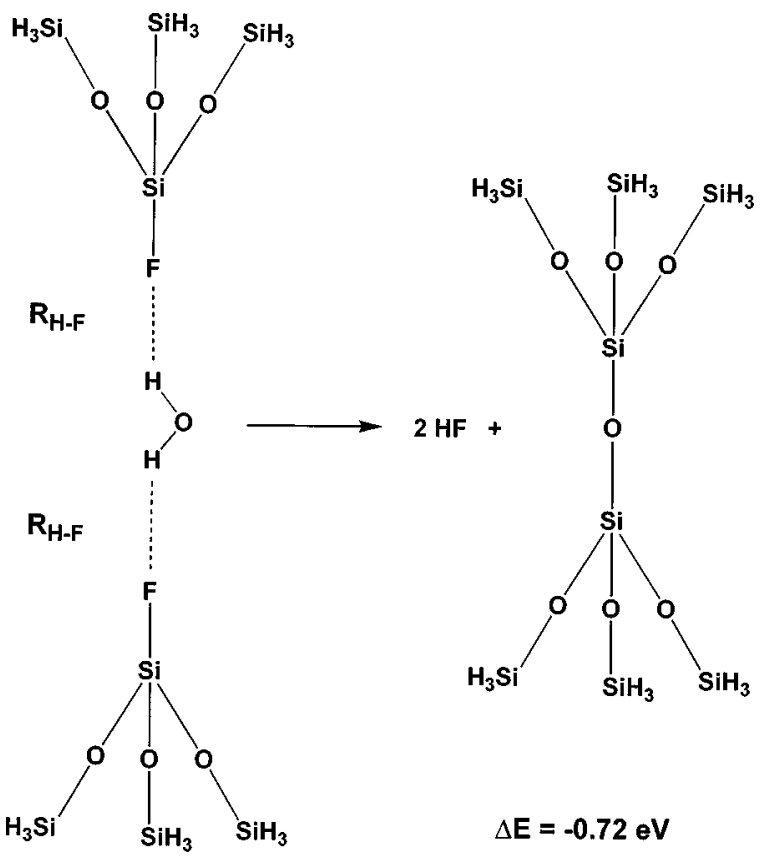

FIG. 2. Reaction energetics and geometries of $2 \mathrm{Si}-\mathrm{F}+\mathrm{H}_{2} \mathrm{O} \rightarrow \mathrm{Si}-\mathrm{O}-\mathrm{Si}+2 \mathrm{HF}$, as calculated by ab initio configuration interaction theory.

molecule are described by the same double-zeta basis with an additional set of $2 p$ functions with an exponent of 0.6 . All of the basis sets accurately describe the atomic and molecular properties and have been widely used in electronic calculations. $^{11-13}$

\section{RESULTS}

Figure 2 shows the interaction between $\mathrm{H}_{2} \mathrm{O}$ and two neighboring $\mathrm{Si}-\mathrm{F}$ bonds. The reaction of $2 \mathrm{Si}-\mathrm{F}$ $+\mathrm{H}_{2} \mathrm{O} \rightarrow \mathrm{Si}-\mathrm{O}-\mathrm{Si}+2 \mathrm{HF}$ is exothermic by $0.72 \mathrm{eV}$, as calcu-

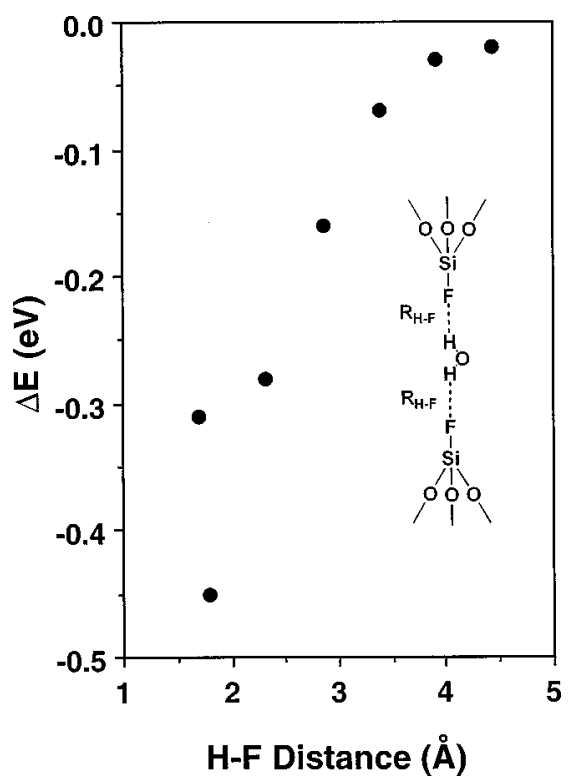

FIG. 3. Interaction energy $\Delta \mathrm{E}$ vs the $\mathrm{H}-\mathrm{F}$ distances. $\Delta \mathrm{E}$ is relative to $2 \mathrm{Si}-\mathrm{F}$ and $\mathrm{H}_{2} \mathrm{O}$ at infinite separation. 


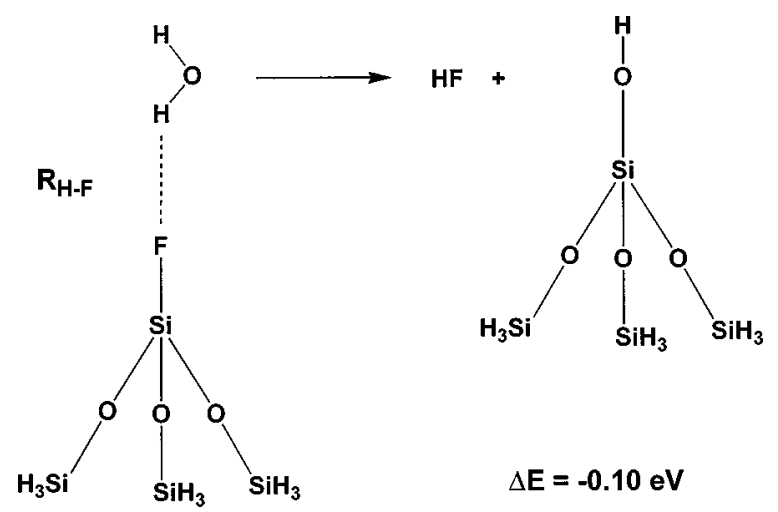

FIG. 4. Reaction energetics and geometries of $\mathrm{Si}-\mathrm{F}+\mathrm{H}_{2} \mathrm{O} \rightarrow \mathrm{Si}-\mathrm{OH}+\mathrm{HF}$, as calculated by $a b$ initio configuration interaction theory.

lated at the configuration interaction level. Figure 3 shows the reaction energetics of $2 \mathrm{Si}-\mathrm{F}+\mathrm{H}_{2} \mathrm{O}$ as a function of the $\mathrm{H}-\mathrm{F}$ distances. The energy minimum occurs at $R_{\mathrm{H}-\mathrm{F}} \sim 1.8 \AA$, with the total energy of the system about $0.45 \mathrm{eV}$ lower than 2Si-F and $\mathrm{H}_{2} \mathrm{O}$ at infinite separation. The insertion of $\mathrm{H}_{2} \mathrm{O}$ into the $\mathrm{Si}-\mathrm{F}$ bonds is due to the strong hydrogen bonding between $\mathrm{F}$ and $\mathrm{H}$ atoms.

Figure 4 depicts the interaction between $\mathrm{H}_{2} \mathrm{O}$ and one neighboring $\mathrm{Si}-\mathrm{F}$ bond. The reaction of $2 \mathrm{Si}-\mathrm{F}$ $+\mathrm{H}_{2} \mathrm{O} \rightarrow \mathrm{Si}-\mathrm{O}-\mathrm{Si}+2 \mathrm{HF}$ is exothermic only by $0.10 \mathrm{eV}$. Figure 5 shows the reaction energetics of $\mathrm{Si}-\mathrm{F}+\mathrm{H}_{2} \mathrm{O}$ as a function of the H-F distances. The energy minimum occurs at $R_{\mathrm{H}-\mathrm{F}} \sim 2.2 \AA$, with the total energy of the system about 0.07 $\mathrm{eV}$ lower than $\mathrm{Si}-\mathrm{F}$ and $\mathrm{H}_{2} \mathrm{O}$ at infinite separation.

Our calculations indicated that a water molecule is much more stable when two Si-F bonds are nearby, and that atmospheric exposure is to reduce the bonded $\mathrm{F}$ content. The reaction pathway of the interaction of the Si-O-F film and water was via near-neighbor $\mathrm{F}$ atom bonding sites, e.g., those

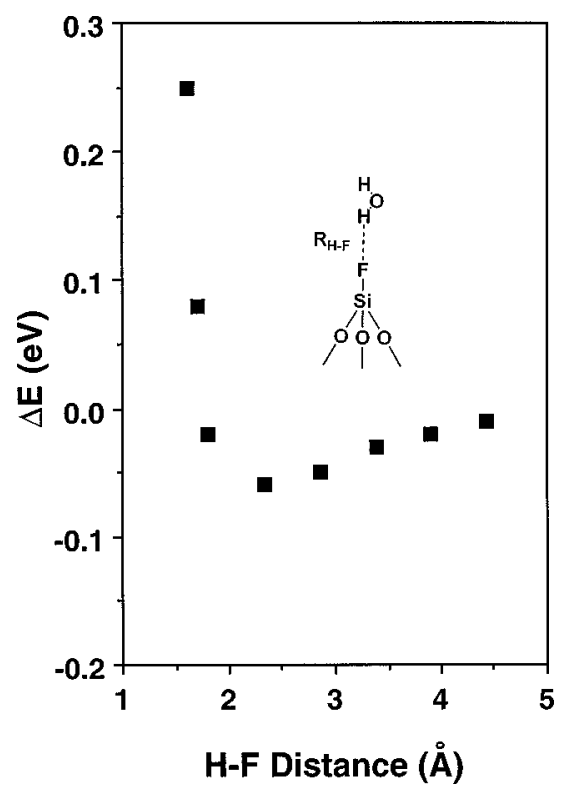

FIG. 5. Interaction energy $\Delta \mathrm{E}$ vs the $\mathrm{H}-\mathrm{F}$ distances. $\Delta \mathrm{E}$ is relative to $\mathrm{Si}-\mathrm{F}$ and $\mathrm{H}_{2} \mathrm{O}$ at infinite separation.
TABLE I. Calculated total energies for molecules and clusters.

\begin{tabular}{|c|c|c|}
\hline \multirow[b]{2}{*}{ Molecule or cluster } & \multicolumn{2}{|c|}{ Total energies (hartree) } \\
\hline & SCF & CI \\
\hline $\mathrm{H}_{2} \mathrm{O}$ & -76.0258 & -76.1332 \\
\hline $\mathrm{HF}$ & -100.0322 & -100.1733 \\
\hline $\mathrm{F}-\mathrm{Si}\left(-\mathrm{OSiH}_{3}\right)_{3}$ & -629.1628 & -629.3298 \\
\hline $\mathrm{HO}-\mathrm{Si}\left(-\mathrm{OSiH}_{3}\right)_{3}$ & -605.1321 & -605.3192 \\
\hline $\mathrm{O}-\left[\mathrm{Si}\left(-\mathrm{OSiH}_{3}\right)_{3}\right]_{2}$ & -563.9278 & -564.0647 \\
\hline
\end{tabular}

with paired Si-F bonding arrangements. As reported in Ref. 4 , since the interaction of $2 \mathrm{Si}-\mathrm{F}+\mathrm{H}_{2} \mathrm{O}$ and thermal annealing dominate when the fraction of Si-F bonding sites occupied exceeds 0.2 of those available, one would expect hydroscopic behavior to become increasingly important when the $\mathrm{F}$ atom concentration begins to exceed $\sim 7$ at. \% (note that complete occupancy of available $\mathrm{F}$ atom bonding sites corresponds to $\sim 28.6$ at. \% F). If the film has been exposed to water vapor resulting in the reduction of the bonded F contents and incorporating nearest-neighbor $\mathrm{Si}-\mathrm{OH}$ groups, then annealing will always result in an increase in dielectric constant as has been reported in Ref. 3 .

Table I lists the total energies as calculated at both selfconsistent-field and configuration interaction levels for $\mathrm{H}_{2} \mathrm{O}$ and $\mathrm{HF}$ molecules and other $\mathrm{Si}-\mathrm{O}$ and $\mathrm{Si}-\mathrm{O}-\mathrm{F}$ clusters using basis sets discussed in Sec. II.

\section{CONCLUSIONS}

In summary, ab initio configuration interaction calculations have been used to study the stability of Si-O-F alloy films with respect to attack of Si-F bonds by water molecules. The present calculations show that the reaction: $\mathrm{H}_{2} \mathrm{O}$ $+2 \mathrm{Si}-\mathrm{F} \rightarrow 2 \mathrm{HF}+\mathrm{Si}-\mathrm{O}-\mathrm{Si}$ is exothermic by about $0.7 \mathrm{eV}$. The reaction energetics is a function of the distance between the $\mathrm{F}$ atoms of the Si-F groups and the $\mathrm{H}$ atoms of $\mathrm{H}_{2} \mathrm{O}$ molecule. Strong hydrogen bonding between $\mathrm{H}$ and $\mathrm{F}$ atoms is found. Combining these calculations for interactions with $\mathrm{H}_{2} \mathrm{O}$ with a statistical model of bonding in the alloy films as presented in our previous article, ${ }^{1}$ an upper limit for chemically stable $\mathrm{F}$ corporation has been determined to be $\sim 10-12$ at. \% F, which corresponds to static dielectric constant of 3.2-3.4.

\section{ACKNOWLEDGMENTS}

Support of the work by the Office of Naval Research and Intel Corporation is gratefully acknowledged.

${ }^{1}$ G. Lucovsky and H. Yang, J. Vac. Sci. Technol. A 15, 836 (1997).

${ }^{2}$ S. W. Lim, Y. Shimogaki, Y. Nakano, K. Tada, and H. Komiyama, Extended Abstracts of the 1995 International Conference on Solid State Device and Materials (Business Center for Academic Societies Japan, Tokyo, 1995), p. 153.

${ }^{3}$ S. W. Lim, Y. Shimogaki, Y. Nakano, K. Tada, and H. Komiyama, Jpn. J. Appl. Phys., Part 1 135, 1468 (1996).

${ }^{4}$ J. A. Theil, D. V. Tsu, S. S. Kim, and G. Lucovsky, J. Vac. Sci. Technol. A 8, 1374 (1990).

${ }^{5}$ P. Cremaschi and J. L. Whitten, Theor. Chim. Acta 72, 485 (1987).

${ }^{6}$ J. L. Whitten and H. Yang, Int. J. Quantum Chem., Quantum Chem. Symp. 29, 41 (1995). 
${ }^{7}$ J. L. Whitten and H. Yang, Surf. Sci. Rep. 24, 55 (1996).

${ }^{8}$ T. H. Dunning, Jr. and P. J. Hay, in Methods of Electronic Structure Theory, edited by H. F. Schafer III (Plenum, New York, 1977), Vol. 3, pp. 1-27.

${ }^{9}$ A. Chattopadhyay, P. V. Madhavan, J. L. Whitten, C. R. Fischer, and I. P. Batra, J. Mol. Struct.: THEOCHEM 163, 63 (1988).
${ }^{10}$ J. L. Whitten, J. Chem. Phys. 44, 359 (1966).

${ }^{11}$ Z. Jing, J. L. Whitten, and G. Lucovsky, Phys. Rev. B 45, 13978 (1992).

${ }^{12}$ H. Yang, Z. Jing, and J. L. Whitten J. Electron Spectrosc. Relat. Phenom., 69, 23 (1994).

${ }^{13}$ E. Srinivasan, H. Yang, and G. N. Parsons, J. Chem. Phys. 105, 5467 (1996). 